\title{
Electrochemically Generated Peryleniumyl-Hexafluorophosphate and Hexafluoroarsenate: New One-Dimensional Metals
}

\author{
H. J. KELLER, D. NÖTHE, H. PRITZKOW, D. WEHE, and M. WERNER \\ Anorganisch-Chemisches Institut der Universität, \\ Im Neuenheimer Feld 270, 6900 Heidelberg. West Germany.
}

and

P. KOCH and D. SCHWEITZER

Max-Planck-Institut für Medizinische Forschung, Abteilung für Molekulare Physik, Jahnstr. 29, 6900 Heidelberg. West Germany.

(Received May 28, 1980)

Compounds of stoichiometry $(\mathrm{pe})_{2}\left(\mathrm{PF}_{6}\right)_{1.1} \times 0.8 \mathrm{CH}_{2} \mathrm{Cl}_{2}(\mathbf{1})\left(\mathrm{pe}=\right.$ perylene), $(\mathrm{pe})_{2}\left(\mathrm{AsF}_{6}\right)_{1.1} \times$ $0.7 \mathrm{CH}_{2} \mathrm{Cl}_{2}(2)$, (pe $)_{2}\left(\mathrm{PF}_{6}\right)_{1.4} \times 0.6 \mathrm{THF}(3),(\mathrm{pe})_{2}\left(\mathrm{AsF}_{6}\right)_{1.5} \times 0.5 \mathrm{THF}(4)$ and $(\mathrm{pe})_{3}\left(\mathrm{SbF}_{6}\right)_{2} \times$ $0.75 \mathrm{CH}_{2} \mathrm{Cl}_{2}(5)$ have been obtained as crystalline samples by electrochemical deposition from $\mathrm{CH}_{2} \mathrm{Cl}_{2}[(1)$, (2) and (5)] or from THF [(3) and (4)] solutions of perylene, containing the appropriate counterion. The three compounds (1)-(3) crystallize in isomorphous orthorhombic lattices. (1) forms black needies: space group Pnmn with $a=4.285 \AA, b=12.915 \AA$ and $c=$ $14.033 \AA, z=1$. (2) gives black needles, orthorhombic space group Pnmn with $a=4.294 \AA$, $b=13.077 \AA$, and $c=14.132 \AA, z=1$. The structures of (1) and (2) were solved by direct methods and refined by least squares to final $R=0.148$ and $R=0.088$ based on 476 and 322 observed reflections. The perylene forms segregated stacks in direction of the $a$-axis with interplanar distances of $3.40 \AA$ and an angle of $37.7^{\circ}$ between the $b c$-plane and the perylene. The channels between the segregated stacks are filled by anions and solvent molecules. The d.c. conductivities (four probe measurements) of (1)-(4) fall in the range of $70-1200 \Omega^{-1} \cdot \mathrm{cm}^{-1}$ at room temperature. The conductivities show a metallic regime down to about $200^{\circ} \mathrm{K}$ and drop off below that temperature. 


\section{INTRODUCTION}

Electrochemically induced redox reactions in organic solvents are a common tool to generate and investigate open shell organic ions. ${ }^{1-3}$ In several cases this procedure led to the isolation of solid products containing radical ions with remarkable solid state properties. ${ }^{4-8}$ The recent interest in crystallized organic radical ions is connected mainly with their high electrical conductivities. ${ }^{9-11}$ Some of the very promising materials have recently been obtained electrochemically. ${ }^{8}$ The electrochemical method is especially well suited in the search for highly conducting (metallic) radical salts. This is because electrochemical deposition of solid organic radical salts from solutions "inevitably" selects in favor of the highly conducting crystals. From all thermodynamically favorable compounds which could crystallize from solution the metallic ones grow fastest. After nucleation at the electrode surface those crystals with the lowest resistivity will enable the most intense electron flow. Only those compounds which allow electron transport for the redox reaction over a distance of several millimeters and in a high density flux can be deposited as reasonable crystals. The advantages of electrocrystallization have been demonstrated earlier by different groups growing single crystals of one-dimensional metals of the mixed valence tetracyanoplatinate (II, IV) type electrochemically. ${ }^{12,13}$

Electrochemical oxidation reactions on several aromatic hydrocarbons have been carried out in this laboratory, following the above mentioned lines. By varying experimental conditions, using different hydrocarbons (like coronene, anthracene, pyrene, triphenylene, etc.) and supporting electrolytes like $\left(\mathrm{C}_{4} \mathrm{H}_{9}\right)_{4} \mathrm{~N}^{+} \mathrm{PF}_{6}^{-},\left(\mathrm{C}_{4} \mathrm{H}_{9}\right)_{4} \mathrm{~N}^{+} \mathrm{AsF}_{6}^{-}$, etc., it was found as a preliminary result that perylene is especially well suited to form highly conducting solid radical species. Structural and physical investigations on some of these solids obtained by electrocrystallization procedures are presented here.

\section{EXPERIMENTAL}

\subsection{Preparation of compounds}

\subsubsection{Apparatus for electrochemical syntheses}

The electrolyses were carried out in a $100 \mathrm{ml}$ U-tube with a glass filter or in a $75 \mathrm{ml}$ electrochemical cell of 3 compartments separated by 2 glass filters from each other. In some cases the crystal size of the reaction products depend on the used electrochemical cell. Platinum wire was used as electrode material. $\mathrm{Ni}, \mathrm{Ag}$ and $\mathrm{Cu}$ can be used as cathode material, too. The potential was selected to give a current of 20-50 $\mu \mathrm{A}$. Depending on the cell, solvent 
and concentration of the supporting electrolyte, potentials between 2.5 and $6 \mathrm{~V}$ have been used. This results in a current density of $2-5 \mu \mathrm{A} / \mathrm{cm}^{2}$. This current density is conclusive for the velocity of the crystal growth.

\subsubsection{Chemicals}

Methylenechloride $\left(\mathrm{CH}_{2} \mathrm{Cl}_{2}\right)$ was dried over $\mathrm{CaCl}_{2}$ and a molecular sieve $4 \AA$ and saturated with nitrogen. Tetrahydrofurane (THF) $99.9 \%$ (GoldMarke) saturated with nitrogen was purchased from EGA Chemie. Tetrabutylammoniumhexafluorophosphate $\left(\mathrm{Bu}_{4} \mathrm{PF}_{6}\right)$ was obtained by mixing equimolar amounts of $\mathrm{Bu}_{4} \mathrm{~N} \mathrm{~J}$ and $\mathrm{KPF}_{6}$ in aqueous solution. ${ }^{14} \mathrm{Bu}_{4} \mathrm{NAsF}_{6}$ was obtained in a similar fashion by using potassium hexafluoroarsenate instead of $\mathrm{K} \mathrm{PF}_{6} . \mathrm{Bu}_{4} \mathrm{NSbF}_{6}$ was prepared in a similar manner as $\left(\mathrm{CH}_{3}\right)_{4} \mathrm{NSbF}_{6} .{ }^{15}$ To a solution of $13.15 \mathrm{~g}$ Potassiumhexahydroxoantimonate (V), $\mathrm{K}\left[\mathrm{Sb}(\mathrm{OH})_{6}\right]$ in $100 \mathrm{ml} 40 \% \mathrm{HF} \mathrm{a} 40 \%$ aqueous solution of Tetrabutylammoniumhydroxide was added. The mixture was evaporated to half of its original volume, the precipitate was filtered and washed with a few milliliters of water. Recrystallization from isopropanol gave white needles, $\mathrm{Fp} .: 220^{\circ} \mathrm{C}$, Yield: $11 \mathrm{~g} \cong 46 \%$ of the theoretical yield.

Analyses: $\left(\mathrm{C}_{4} \mathrm{H}_{9}\right)_{4} \mathrm{NSbF}_{6}$ Molemass: 478.22

Calc.: C $40.19 \%$ H $7.59 \% \quad$ N $2.93 \%$

Found: C $40.19 \%$ H $7.79 \% \quad$ N $2.80 \%$

All these supporting electrolytes were dried under high vacuum. Perylene $99+\%$ Gold label was purchased from Aldrich Chemical Company and used without further purification.

\subsubsection{Preparation of pe- $P F_{6}$ compounds}

2.1.3.1 $(p e)_{2}\left(\mathrm{PF}_{6}\right)_{1.1} \times 0.8\left(\mathrm{CH}_{2} \mathrm{Cl}_{2}\right)$. $0.1 \mathrm{~g}$ perylene and $0.5 \mathrm{~g} \mathrm{Bu}_{4} \mathrm{NPF}_{6}$ were dissolved in $100 \mathrm{ml}$ absolute $\mathrm{CH}_{2} \mathrm{Cl}_{2}$, filtrated into the electrochemical cell and electrolized by applying about $3 \mathrm{~V}$ and $30 \mu \mathrm{A}$ for about 2 days under exclusion of light. Crystal growth starts after a few minutes and after two days black needles (which appear green by looking through the crystals), of several $\mathrm{cm}$ in length, were obtained. A typical experiment is shown in Figure 1. The crystals decompose above $180^{\circ} \mathrm{C}$, giving up neutral perylene.

Analyses: $(\mathrm{pe})_{2}\left(\mathrm{PF}_{6}\right)_{1,1} \times 0.8 \mathrm{CH}_{2} \mathrm{Cl}_{3}$ :

Molemass: 732.06

$$
\mathrm{C}_{40.8} \mathrm{H}_{25.6} \mathrm{Cl}_{1.6} \mathrm{~F}_{6.6} \mathrm{P}_{1.1}
$$

$\begin{array}{llllll}\text { Calc.: } & \text { C 66.94 } & \text { H } 3.52 & \text { Cl } 7.75 & \text { F } 17.13 & \text { P } 4.65 \\ \text { Found: } & \text { C 66.71 } & \text { H } 3.66 & \text { Cl } 8.05 & \text { F 17.00 } & \text { P } 4.50 \\ \text { C 66.57 } & \text { H 3.72 } & & & \text { P } 4.53\end{array}$


Closer inspection of the prepared samples showed, that principally two different types of crystals grow simultaneously at the surface of the anode: thinner ones with a rectangular or trapezoid cross-section ("type one") while the thicker ones have rectangular, quadratic or preferably hexagonal cross-sections ("type two"), (for typical dimensions see Section 2.3. "Conductivity measurements"). The latter crystals are the main product during electrocrystallization.

Analytical data suggest that type one crystals contain much less $\mathrm{CH}_{2} \mathrm{Cl}_{2}$ but more $\mathrm{PF}_{6}^{-}$ions than the main product. This results in a higher formal oxidation number for the peryleniumyl stacks in "type one" crystals compared to the "type two" modification. The analytical data of the mixture which are given above are very close to the values of the main product (type two).

2.1.3.2 $(p e)_{2}\left(P F_{6}\right)_{1.4} \times 0.6(T H F)$. By using THF instead of $\mathrm{CH}_{2} \mathrm{Cl}_{2}$ as solvent the same condition with a current of $20 \mu \mathrm{A}$ leads after two days to long but very thin black needles. No "type two" crystals have been observed. The crystals decompose above $170^{\circ} \mathrm{C}$. Above this temperature perylene crystals grow at the surface of the black needles.

Analyses: $(\mathrm{pe})_{2}\left(\mathrm{PF}_{6}\right)_{1.4} \times 0.6 \mathrm{THF}$

$$
\mathrm{C}_{42.4} \mathrm{H}_{28.8} \mathrm{O}_{0.6} \mathrm{P}_{1.4} \mathrm{~F}_{8.2}
$$

Molemass: 751.46

Calc.: $\quad$ C $67.77 \quad$ H $3.86 \quad$ F $21.24 \quad$ O $1.28 \quad$ P 5.77

Found: C 67.48 H 3.96 F $20.62 \quad$ O $-\quad$ P 5.77

\subsubsection{Preparation of pe-As $F_{6}$ compounds}

2.1.4.1 $(p e)_{2}\left(\mathrm{AsF}_{6}\right)_{1.1} \times 0.7\left(\mathrm{CH}_{2} \mathrm{Cl}_{2}\right)$. The electrocrystallization was carried out with the same apparatus and under the same conditions just using $\mathrm{Bu}_{4} \mathrm{NAsF}_{6}$ instead of $\mathrm{Bu}_{4} \mathrm{NPF}_{6}$. Long black needles are obtained (green in absorption) which decompose above $260^{\circ} \mathrm{C}$ giving up neutral perylene.

Analyses: $(\mathrm{pe})_{2}\left(\mathrm{AsF}_{6}\right)_{1.1} \times 0.7 \mathrm{CH}_{2} \mathrm{Cl}_{2}$

$$
\left(\mathrm{C}_{40.7} \mathrm{H}_{25.4} \mathrm{As}_{1.1} \mathrm{Cl}_{1.4} \mathrm{~F}_{6.6}\right)
$$

Molemass: 771.90

Calc. $\quad$ C $63.34 \quad$ H $3.32 \quad$ As $10.62 \quad$ Cl $6.42 \quad$ F 16.25

Found: C $63.30 \quad$ H $3.44 \quad$ As $10.8 \quad$ Cl $6.20 \quad$ F 17.0

Again two different types of crystals (thinner and thicker ones) have been obtained simultaneously at the anode. The results are very similar to those described for the $\mathrm{PF}_{6}^{-}$-derivatives (see Sections 2.1.3.1. and 2.3). 


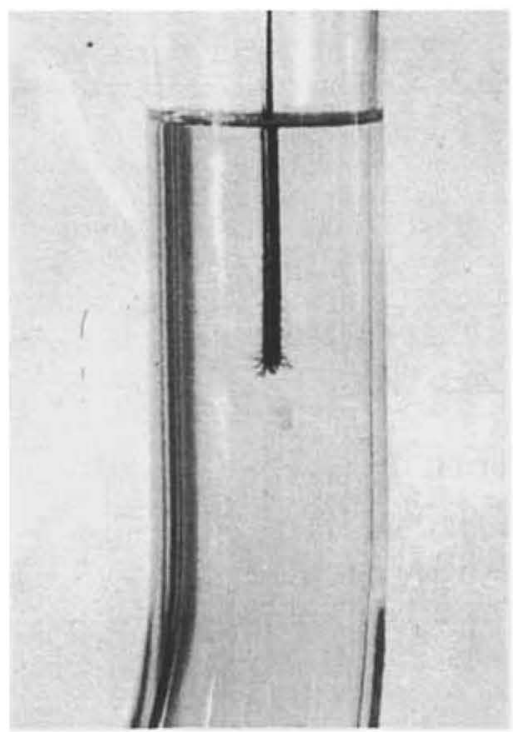

(a)

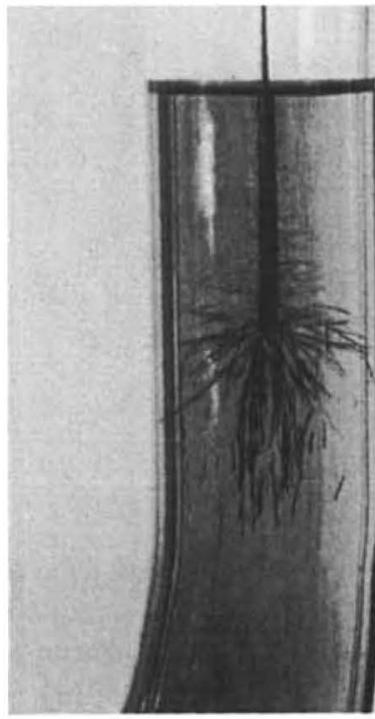

(c)

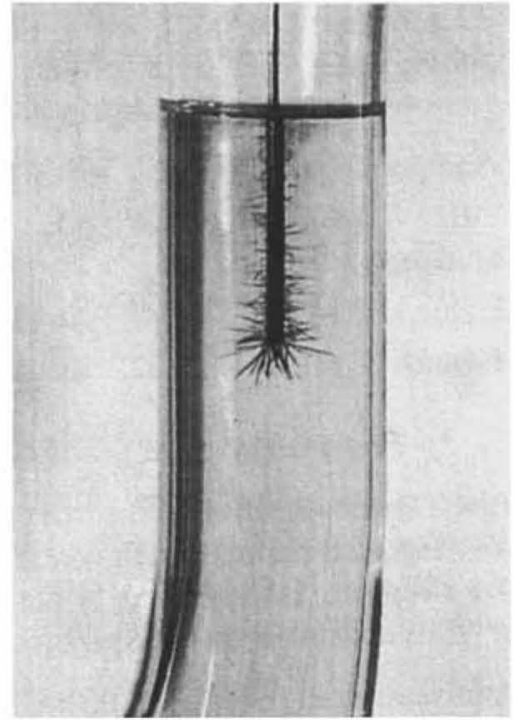

(b)

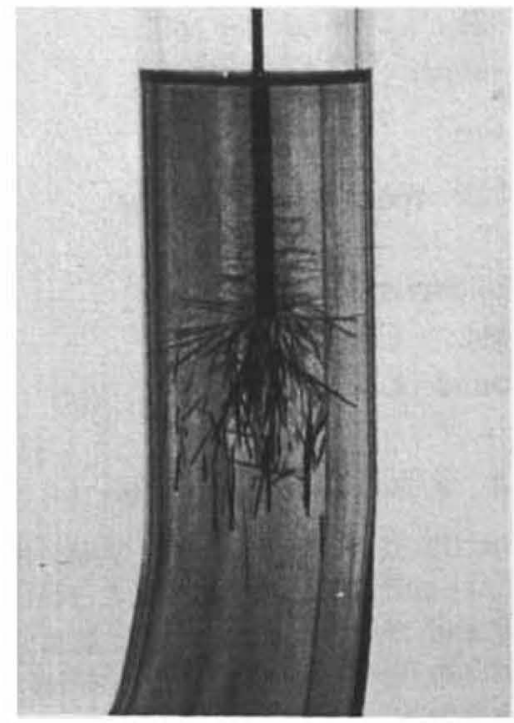

(d)

FIGURE I Electrocrystallization of ( $I$ ) at a platinum anode: (a) after $30 \mathrm{~min}$. (b) after $2 \mathrm{~h}$, (c) after $12 \mathrm{~h},(\mathrm{~d})$ after $20 \mathrm{~h}$. (Only the anode half cell is shown). 
2.1.4.2 $(p e)_{2}\left(A s F_{6}\right)_{1.5} \times 0.5(T H F)$. Similar procedures as described above, using THF as a solvent, give black long but thin needles which decompose above $260^{\circ} \mathrm{C}$. Again no second phase has been found.

Analyses: $(\mathrm{pe})_{2}\left(\mathrm{AsF}_{6}\right)_{1.5} \times 0.5 \mathrm{THF}$

$$
\mathrm{C}_{42} \mathrm{H}_{28} \mathrm{As}_{1.5} \mathrm{~F}_{9.2} \mathrm{O}_{0.5}
$$

Molemass: 824.08

Calc.: C 61.22 H 3.42 As 13.67 F $21.21 \quad$ O 0.97

Found: C 60.92 H 3.32 As 14.1 F 20.38 O-

\subsubsection{Preparation of $(p e)_{3}(\mathrm{SbF})_{2}$ compounds}

Electrocrystallization from $\mathrm{CH}_{2} \mathrm{Cl}_{2}$ and from THF gives small black platelets and prisms which cover the electrode but which do not grow into the solution. Only $\mathbf{C}$ and $\mathbf{H}$ analyses have been carried out because the crystals are not usable for physical investigations.

Analyses: $(\mathrm{pe})_{3}\left(\mathrm{SbF}_{6}\right)_{2} \times 0.75 \mathrm{CH}_{2} \mathrm{Cl}_{2}$

$$
\mathrm{C}_{60.75} \mathrm{H}_{37.5} \mathrm{Cl}_{1.5} \mathrm{~F}_{12} \mathrm{Sb}_{2}
$$

Molemass: 1292.16

Calc.: C $56.67 \quad$ H 2.93

Found: C 56.74 H 3.14

from

THF: $(\mathrm{pe})_{3}\left(\mathrm{SbF}_{6}\right)_{2} \times \mathrm{THF}$

$\mathrm{C}_{64} \mathrm{G}_{44} \mathrm{~F}_{12} \mathrm{Sb}_{2}$

Molemass: 1300.57

Calc.: C $59.10 \quad$ H 3.41

Found: C 58.93 H 3.62

\subsection{X-Ray investigations}

For the collection of the X-ray intensity data only the type two crystals of (1) and (2) could be used. Nevertheless we investigated thin crystals of (3) and showed them to be isomorphous with the type two phases of (1) and (2) (see Table I). There seems to be no doubt that all phases of (1)-(4) are isostructural.

Lattice parameters were determined from Weissenberg films and refined with 22 for (1) respectively 19 for (2) reflections measured on a Syntex R3 diffractometer. Intensity data were collected on the diffractometer $\left(\mathrm{MoK}_{\alpha}\right.$ radiation, $\lambda=0.7107 \AA$, graphite monochromator). Reflections were measured by $\theta / 2 \theta$ scan with a scan range of $1.9^{\circ}$. Crystal data and details of 
TABLE I

\begin{tabular}{lccc}
\hline Compound & $(1)$ & $(2)$ & $(3)$ \\
Crystal System & orthorhombic & orthorhombic & orthorhombic \\
Space group & Pnmn & Pnmn & Pnmn \\
Cell parameters a $(\AA)$ & 4.285 & 4.294 & $4.26^{\mathrm{a}}$ \\
\multicolumn{1}{c}{$\mathrm{b}(\AA)$} & 12.915 & 13.077 & $12.79^{\mathrm{a}}$ \\
$\mathrm{c}(\AA)$ & 14.033 & 14.132 & $13.89^{\mathrm{a}}$ \\
Cell volume $(\AA)$ & 776.56 & 793.55 & $756.80^{\mathrm{a}}$ \\
$z$ & 1 & 1 & 1 \\
Density calc. $\left(\mathrm{g} / \mathrm{cm}^{3}\right)$ & 1.57 & 1.65 & 1.61 \\
Linear absorption factor $\left(\mathrm{cm}^{-1}\right)$ & 13.0 & 12.1 & - \\
Size of crystal $(\mathrm{mm})$ & $0.5 \times 0.2 \times 0.1$ & $0.3 \times 0.2 \times 0.1$ & $0.3 \times 0.2 \times 0.05$ \\
28 max. & 67.6 & 69.6 & - \\
Number of measured refl. & 781 & 1226 & - \\
Unobserved refl. & 305 & 904 & - \\
\hline
\end{tabular}

${ }^{a}$ Cell parameters from Weissenberg films were not refined by diffractometer data.

measurements are given in Table I). LP and absorption corrections were applied to the data. Reflections with $I<3 \sigma(I)$ were considered unobserved and not included in the refinement. The calculations were carried out on an IBM 370/168-computer (Universitäts-Rechenzentrum, Heidelberg).

\subsection{Conductivity measurements}

The dc-conductivity was measured by the standard four-probe method ${ }^{16}$ along the needle axis (length $2-4 \mathrm{~mm}$ ) parallel to the perylene stacks. The samples were mounted on gold wires in a Teflon block as described by Coleman. ${ }^{17}$ The current and voltage contacts were made with silver(Dupont 4929) or gold-paint (Doduco Auromal GM7). The current contacts covered the ends of the crystal to assure uniform current distribution. Currents from 0.5-10 $\mu \mathrm{A}$ (HP 4329A) were used for the measurements. The voltage contacts were carefully painted completely around the crystal. The voltage was measured with a Digital Nanovoltmeter (Keithley Model 180). The samples were placed in a continuous flow cryostat (Oxford Instruments CF 204 with Digital Temperature Controller DTC-2) for lowering the temperature.

The temperature dependence of the conductivity was measured on about twenty $(\mathrm{pe})_{2}\left(\mathrm{PF}_{6}\right)_{1.1} \times 0.8 \mathrm{CH}_{2} \mathrm{Cl}_{2}$ crystals. The room temperature conductivity $\sigma_{(300)}$ for these crystals varied between $160(\Omega \mathrm{cm})^{-1}$ and 1.100 $(\Omega \mathrm{cm})^{-1}$. A typical value for the majority of the samples was about 600 $(\Omega \mathrm{cm})^{-1}$. Very similar results were obtained for the $(\mathrm{pe})_{2}\left(\mathrm{AsF}_{6}\right)_{1.1} \times 0.7$ $\mathrm{CH}_{2} \mathrm{Cl}_{2}$ crystals. The room temperature conductivity $\sigma_{(300)}$ varied between $210(\Omega \mathrm{cm})^{-1}$ and $1200(\Omega \mathrm{cm})^{-1}$, a typical value was about $700(\Omega \mathrm{cm})^{-1}$.

For (1) as well as for (2) two types of crystals were measured. The first type of crystals was very thin $(\sim 0.005-0.01 \mathrm{~mm})$ and at least 10 to 50 
times as broad, while the second type of crystals was thicker $(\sim 0.05 \mathrm{~mm})$ and only 1 to 3 times as broad. The room temperature conductivities of both types of crystals are comparable but the temperature dependence is somewhat different. Figure 2 shows the typical temperature dependence of the conductivity normalized to the room temperature value $\sigma_{(300)}$ for the type one crystals of (1) and (2). Figure 3 shows the same temperature dependence for the second type of crystals. The main difference of both conductivity characteristics is that in the second case the conductivity makes a sudden jump at a temperature of about $110-120 \mathrm{~K}$. In the moment it is not clear if this change in conductivity is due to a phase transition.

In the case of (3) and (4) only one type of crystal is found [similar to the type one crystals of (1) and (2)]. The room temperature conductivity $\sigma_{(300)}$ of these crystals of (3) and (4) varied between 70 and $700(\Omega \mathrm{cm})^{-1}$ and is therefore somewhat lower than the r.t. conductivity of both forms of (1) and (2).

The temperature dependence of the normalized conductivity of (3) and (4) is shown in Figure 4 and is similar to the one of type one crystals of (1) and (2) in Figure 2. Nevertheless, in the semiconducting region below $180 \mathrm{~K}$ the observed activation energy for (3) and (4) is only about half as large as for type one of (1) and (2).

\subsection{EPR measurements}

X-Band EPR spectra were taken on a Bruker B-ER 420 spectrometer equipped with a Bruker B-NM 12 NMR Gaussmeter for field calibration. Absorption intensities were obtained by double integration of the usual first derivative lines by means of a Bruker ASPECT 2000 computer.

EPR spectra of three thick (type two) single crystals of (1) show one strong, exchange narrowed line of Lorentzian shape. The peak to peak linewidth of only 0.6 Gauss remains constant between $300 \mathrm{~K}$ and $190 \mathrm{~K}$. Below that temperature the linewidth slightly increases with decreasing temperature, being 0.8 Gauss at $100 \mathrm{~K}$. The EPR absorption intensity is constant within $\pm 2 \%$ from $300 \mathrm{~K}$ down to $190 \mathrm{~K}$. At lower temperatures one observes an activated paramagnetism. Because of the small temperature interval in which that paramagnetism could be observed in our experiment the activation energy can be given only very roughly. We estimate the value as $0.025 \mathrm{eV}$.

\section{STRUCTURE DETERMINATION}

The structure determination of (2) is described in detail. The structure was solved in the space group Pnmn by direct methods using the SHELX 76 program. The highest peaks in the $E$-map are assigned to the carbon atoms of 


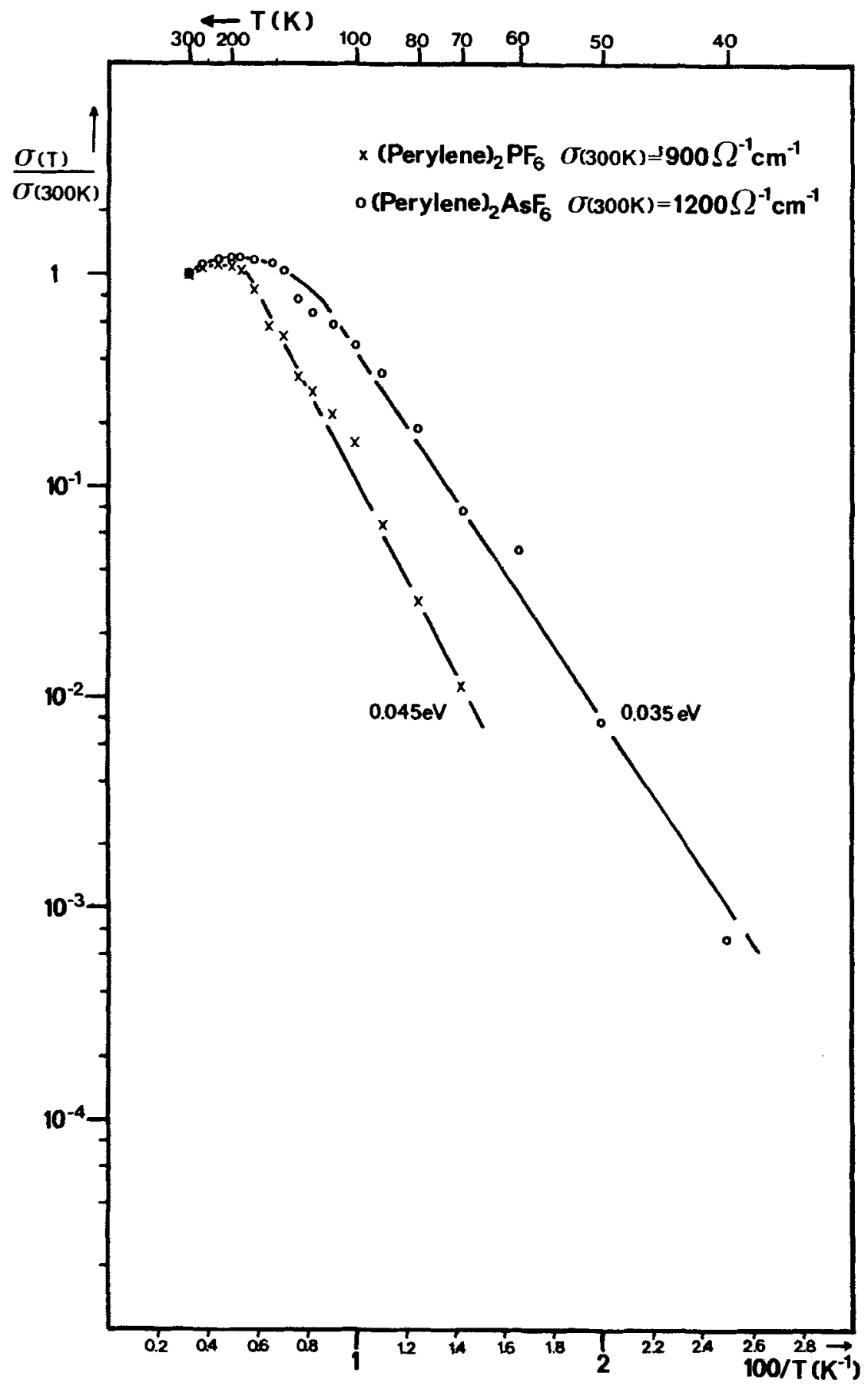

FIGURE 2 Temperature dependence of the normalized d.c. conductivity of "thin" crystals (first type: see text) of (1) ["(Perylene) ${ }_{2} \mathrm{PF}_{6}$ "] and (2) ["(Perylene) ${ }_{2} \mathrm{AsF}_{6}$ "]. 


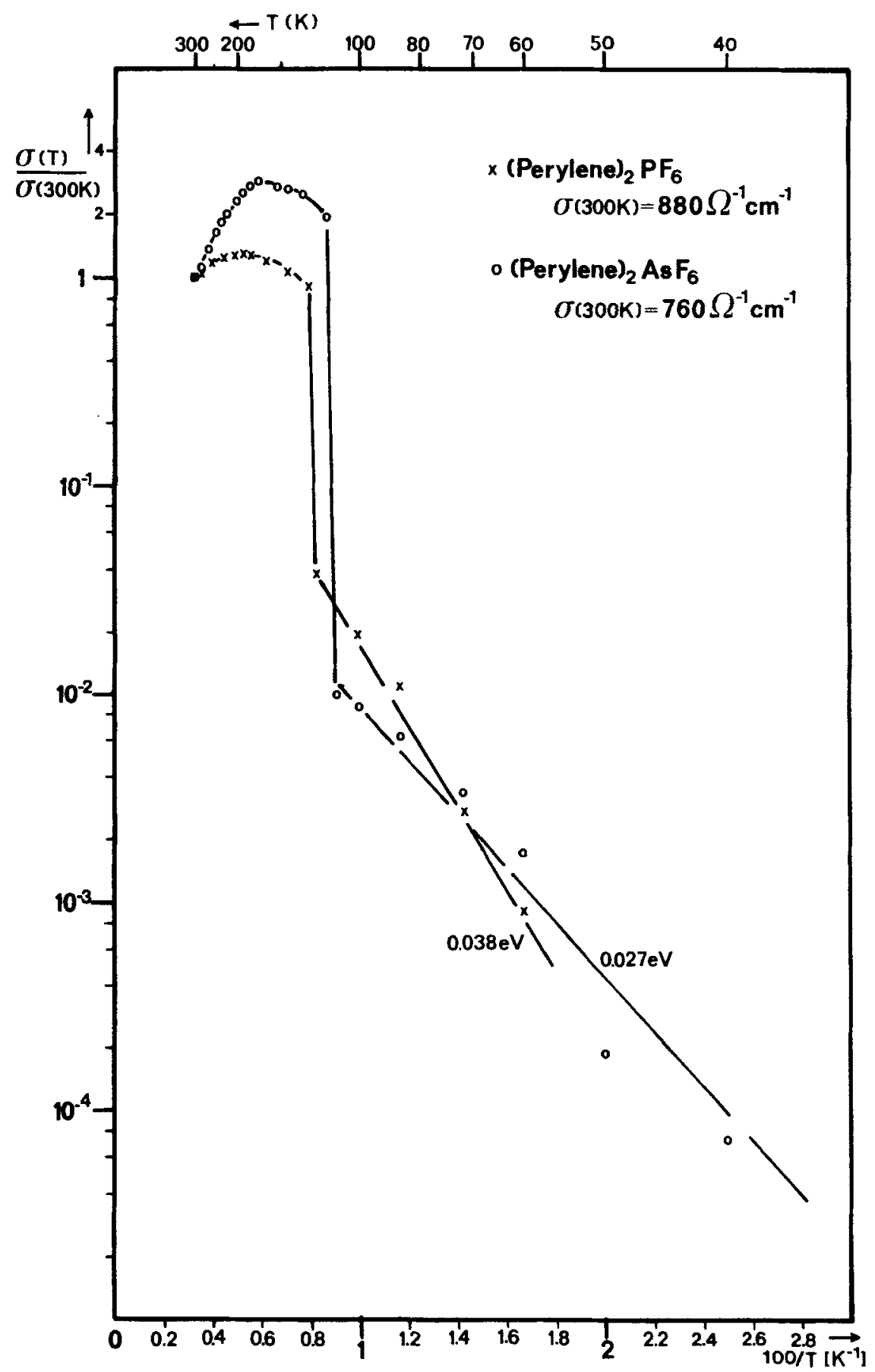

FIGURE 3 Temperature dependence of the normalized d.c. conductivity of "thick" (second type: see text) of (1) and (2). 


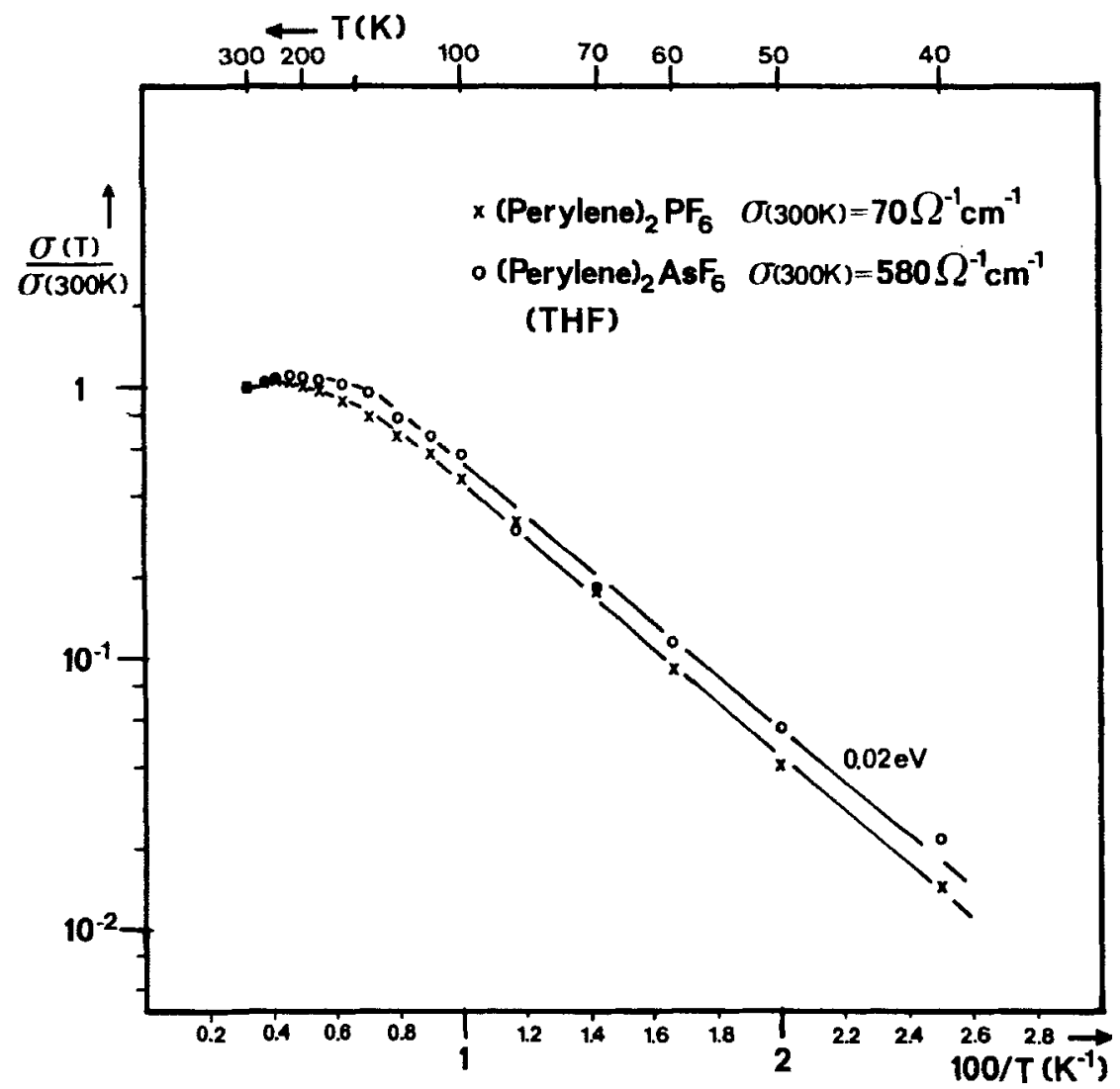

FIGURE 4 Temperature dependence of the normalized d.c. conductivity of (3) ["(Perylene $)_{2} \mathrm{PF}_{6}$ (THF)"] and (4) [“(Perylene $)_{2} \mathrm{AsF}_{6}(\mathrm{THF})$ "'].

the perylene, which lies in the special position $2 b\left(0, \frac{1}{2}, 0\right)$. The perylene molecules form isolated stacks in the direction of the a-axis with a translational period of $4.29 \AA$. The channels between these stacks are filled by anions and solvent molecules. The localization of these molecules is more difficult. Another strong peak in the special position $2 \mathrm{a}(0,0,0)$ gives the position of the As atom, but the peak height is too small and no $F$ atoms can be found. As the chemical analysis gives a perylene: $\mathrm{AsF}_{6}$ ratio of $2: 1.1$, the special position 2a can only partially be occupied by anions. Considering the cell and the form of the anion this is sensible. In the direction of the a-axis the distance between anions in the same channel would come to $4.29 \AA$, less than the shortest extension of the anion. Therefore, only every second cell in a channel is occupied by an anion, the holes between are filled by solvent molecules. This distribution gives a perylene: $A_{s F_{6}}$ ratio of $2: 1$. With an 
analysis ratio of $2: 1.1$, some anions have to occupy adjacent cells in the same channel. This is only possible, if they are shifted from one another in the direction of the a-axis. The very big anisotropic temperature factor in this direction for As (see Table III) may be produced by this displacement. In the case of an ordered arrangement the cell parameter has to be doubled and in the reciprocal space intermediate layers must appear, to which only the anions and solvent molecules would contribute. On rotation photographs of (2) diffuse streaks appear in the middle between the layers perpendicular to a. We conclude from this that the distribution in the channels has a translational period of $2 a$, but without correlation between different channels in the bc plane. A refinement with all carbon atoms and the As atom gives $R=0.27$. The difference Fourier map shows several peaks around the As atom. Three of these form with the As atom an octrahedron with distances of about $1.7 \AA$ and angles of $90^{\circ}$. The mirror plane of the space group goes through the $\mathrm{AsF}_{6}$-octahedron, but doesn't coincide with the

TABLE II

\begin{tabular}{lcccc}
\multicolumn{5}{c}{ Coordinates and temperature factors for $(\mathrm{pe})_{2} \mathrm{PF}_{6}\left(\mathrm{CH}_{2} \mathrm{Cl}_{2}\right)$} \\
\hline & $x$ & $y$ & $z$ & $U_{11}$ \\
\hline $\mathrm{C}(1)$ & 0.0936 & 0.5000 & 0.8314 & 0.0463 \\
& $(0.0050)$ & & $(0.0014)$ & $(0.0052)$ \\
$\mathrm{C}(2)$ & 0.2999 & 0.5000 & 0.9189 & 0.0387 \\
& $(0.0047)$ & & $(0.0013)$ & $(0.0046)$ \\
$\mathrm{C}(3)$ & 0.3985 & 0.5955 & 0.9592 & 0.0392 \\
& $(0.0029)$ & $(0.0010)$ & $(0.0008)$ & $(0.0028)$ \\
$\mathrm{C}(4)$ & 0.2901 & 0.6871 & 0.9204 & 0.0507 \\
& $(0.0036)$ & $(0.0011)$ & $(0.0010)$ & $(0.0039)$ \\
$\mathrm{C}(5)$ & 0.0800 & 0.6853 & 0.8394 & 0.0577 \\
& $(0.0040)$ & $(0.0012)$ & $(0.0011)$ & $(0.0043)$ \\
$\mathrm{C}(6)$ & -0.0094 & 0.5938 & 0.7999 & 0.0559 \\
& $(0.0034)$ & $(0.0012)$ & $(0.0009)$ & $(0.0037)$ \\
$\mathrm{H}(1)$ & 0.2450 & 0.7685 & 0.9025 & 0.05 \\
$\mathrm{H}(2)$ & 0.3143 & 0.7009 & 0.8086 & 0.05 \\
$\mathrm{H}(3)$ & -0.1626 & 0.6169 & 0.7403 & 0.05 \\
$\mathrm{P}$ & 0.0000 & 0.0000 & 1.0000 & $(1)$ \\
$\mathrm{F}(1)$ & 0.2577 & 0.0816 & 0.9676 & 0.0438 \\
& $(0.0145)$ & $(0.0045)$ & $(0.0040)$ & $(0.0133)$ \\
$\mathrm{F}(2)$ & 0.1330 & -0.0776 & 0.4263 & 0.0238 \\
& $(0.0143)$ & $(0.0053)$ & $(0.0046)$ & $(0.0146)$ \\
$\mathrm{F}(3)$ & 0.1858 & -0.0412 & 0.5623 & 0.1675 \\
& $(0.0155)$ & $(0.0047)$ & $(0.0047)$ & $(0.0264)$ \\
$\mathrm{Cl}(1)$ & -0.0361 & 0.0397 & 0.5979 & 0.0724 \\
& $(0.0099)$ & $(0.0026)$ & $(0.0026)$ & $(0.0097)$ \\
& & &
\end{tabular}

(1) Temperature factors for $P$ :

\begin{tabular}{cccccc}
$U_{11}$ & $U_{22}$ & $U_{33}$ & $U_{23}$ & $U_{13}$ & $U_{12}$ \\
\hline 0.1375 & 0.0419 & 0.0637 & 0.0 & -0.0488 & 0.0 \\
$(0.0209)$ & $(0.0084)$ & $(0.0103)$ & & $(0.0130)$ & \\
\hline
\end{tabular}


mirror plane of the octahedron, thus producing two orientations for $\mathrm{AsF}_{6}$. Two other peaks are assigned to the chlorine atoms of $\mathrm{CH}_{2} \mathrm{Cl}_{2}$. A refinement with all non-hydrogen atoms (As anisotropic) lowers the $R$-values to $R=$ 0.102 and $R_{w}=0.077$, adding the H-atoms in calculated positions gives the final values of $R=0.088$ and $R_{w}=0.061$.

For (1) similar results were obtained. But the assignment of the peaks around the $\mathrm{P}$ gave no reasonable results. Thus we assume that the smaller $\mathrm{PF}_{6}$ octahedron is not as well fixed in the available space between the cation stacks and thus no special orientation for $\mathrm{PF}_{6}$ could be found.

Rotation- and Weissenberg-photographs of (3) agreed exactly with that of (1).

\section{DESCRIPTION OF THE STRUCTURE}

Tables II and III show the atom coordinates and temperature factors for (1) and (2) respectively. The coordinates for the carbon atoms show the similarity of the structures of both compounds (1) and (2). The perylene molecule occupies the special position $2 \mathrm{~b}\left(0, \frac{1}{2}, 0\right)$. The angle between the perylene and the bc-plane is $37.7^{\circ}$ and the intermolecular distance is $3.40 \AA$. Atomic distances and angles of the perylene ion in (2) with the standard deviations are shown in Figure 5. Figure 6 shows a projection of two adjacent perylenium cations perpendicular to the perylene plane. A projection of the

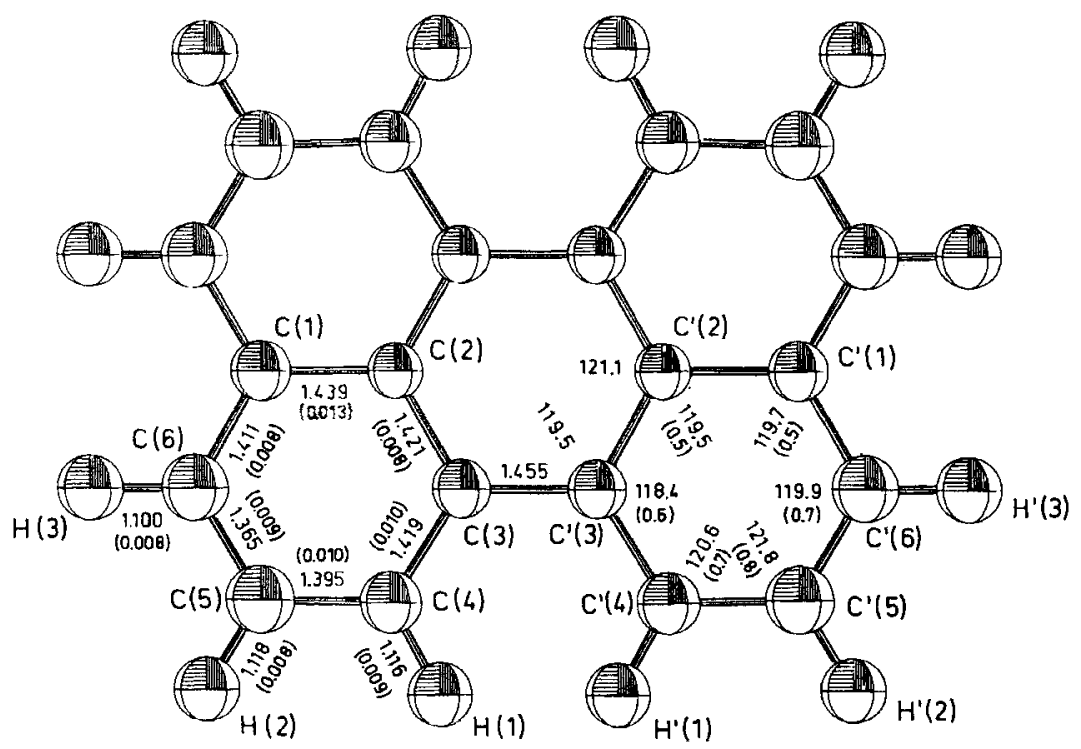

FIGURE 5 Atom distances and angles of the peryleniumyl ion in (2). 
TABLE III

Coordinates and temperature factors for $(\mathrm{pe}){ }_{2} \mathrm{AsF}_{6}\left(\mathrm{CH}_{2} \mathrm{Cl}_{2}\right)$

\begin{tabular}{|c|c|c|c|c|c|}
\hline & $x$ & $y$ & & $z$ & $U_{I 1}$ \\
\hline \multirow[t]{2}{*}{$C(1)$} & 0.0960 & 0.5000 & & 386 & 0.0427 \\
\hline & $(0.0025)$ & $(0.0)$ & & 008) & $(0.0028)$ \\
\hline \multirow[t]{2}{*}{$\mathrm{C}(2)$} & 0.2999 & 0.5000 & & 194 & 0.0367 \\
\hline & $\begin{array}{c}(0.0025) \\
03967\end{array}$ & $\begin{array}{l}(0.0) \\
0.5946\end{array}$ & & $\begin{array}{l}008) \\
592\end{array}$ & $\begin{array}{c}(0.0028) \\
0.0407\end{array}$ \\
\hline$C(3)$ & $\begin{array}{c}0.390 \prime \\
(0.0016)\end{array}$ & $(0.0006)$ & & 005 ) & $\begin{array}{l}0.0407 \\
(0.0020)\end{array}$ \\
\hline \multirow[t]{2}{*}{$C(4)$} & 0.2863 & 0.6865 & & $177^{\prime}$ & 0.0462 \\
\hline & $(0.0019)$ & $(0.0006)$ & & 006) & $(0.0023)$ \\
\hline \multirow[t]{2}{*}{$C(5)$} & 0.0895 & 0.6838 & & 392 & 0.0563 \\
\hline & $(0.0020)$ & $(0.0006)$ & & 006) & $(0.0024)$ \\
\hline \multirow[t]{2}{*}{$C(6)$} & -0.0074 & 0.5937 & & 002 & 0.0520 \\
\hline & $(0.0021)$ & $(0.0006)$ & & 005) & $(0.0021)$ \\
\hline$H(1)$ & 0.3639 & 0.7617 & & 468 & 0.05 \\
\hline $\mathrm{H}(2)$ & 0.0053 & 0.7575 & & 082 & 0.05 \\
\hline $\mathbf{H}(3)$ & -0.1686 & 0.5942 & & 397 & 0.05 \\
\hline As & 0.0000 & 0.0000 & & 000 & (1) \\
\hline \multirow[t]{2}{*}{$F(1)$} & 0.2641 & 0.0549 & & 259 & 0.1668 \\
\hline & $(0.0037)$ & $(0.0019)$ & & 041) & $(0.0042)$ \\
\hline \multirow[t]{2}{*}{$F(2)$} & 0.6913 & 0.0837 & & 601 & 0.1207 \\
\hline & $(0.0032)$ & $(0.0016)$ & & 013) & $(0.0041)$ \\
\hline \multirow[t]{2}{*}{$F(3)$} & 0.0906 & 0.0723 & & 902 & 0.2853 \\
\hline & $(0.0032)$ & $(0.0014)$ & & 012) & $(0.0037)$ \\
\hline \multirow[t]{2}{*}{$\mathrm{Cl}(1)$} & -0.0553 & -0.0958 & & 478 & 0.1386 \\
\hline & $(0.0042)$ & $(0.0031)$ & & 028) & $(0.0043)$ \\
\hline \multirow[t]{2}{*}{$\mathrm{Cl}(2)$} & -0.0248 & -0.0217 & & 071 & 0.0735 \\
\hline & $(0.0040)$ & $(0.0023)$ & & 017) & $(0.004 \mathrm{I})$ \\
\hline$H(4)^{a}$ & -0.2311 & 0.0280 & & 846 & 0.05 \\
\hline$H(5)^{a}$ & -0.1699 & 0.0565 & & 791 & 0.05 \\
\hline \multicolumn{3}{|c|}{ (1) Temperature factors for As: } & & & \\
\hline & 2.22 & & $U_{23}$ & & $U_{12}$ \\
\hline $\begin{array}{r}0.1668 \\
(0.0037)\end{array}$ & $\begin{array}{r}0.0341 \\
(0.0023)\end{array}$ & $\begin{array}{r}0.0507 \\
(0.0026)\end{array}$ & 0.0 & & 0.0 \\
\hline
\end{tabular}

a $\mathrm{H}$-atoms for $\mathrm{CH}_{2} \mathrm{Cl}_{2}$ in the $\mathrm{AsF}_{6}$ compound.

unit cell on the bc-plane shows Figure 7, the anions, which lie between the perylene cations are omitted. A cation stack shows Figure 8. This corresponds to a projection onto the ac-plane. The distances and angles of the perylene ion are in agreement with the values found for perylene. ${ }^{18}$ Because of the agreement of the structures of perylene $\left[\mathrm{Pt}(\mathrm{mnt})_{2}\right]^{19}$ and the present compound it must be assumed that the perylene determines the structure by making segregated stacks, whereas the remaining place is filled by anions. In this case the place is filled by $\mathrm{AsF}_{6}$ and $\mathrm{CH}_{2} \mathrm{Cl}_{2}$, where the $\mathrm{AsF}_{6}$ octahedron has an orientation between the cation stacks, which gives a suitable 


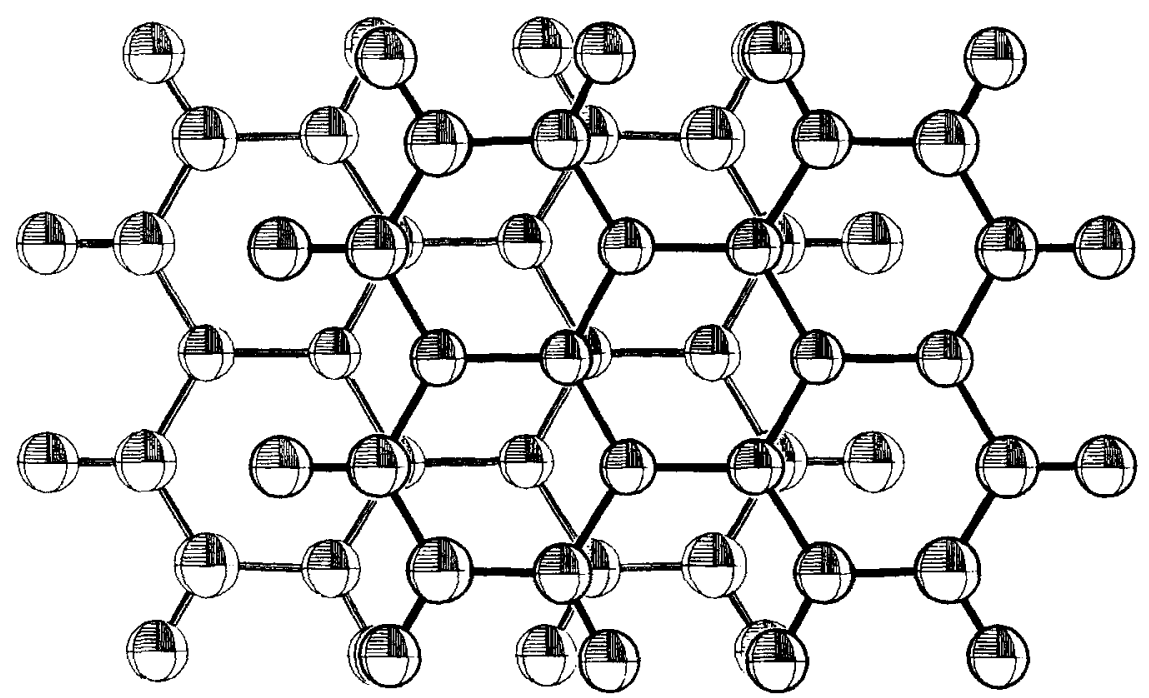

FIGURE 6 Projection of two adjacent perylenium ions perpendicular to the perylene plane.

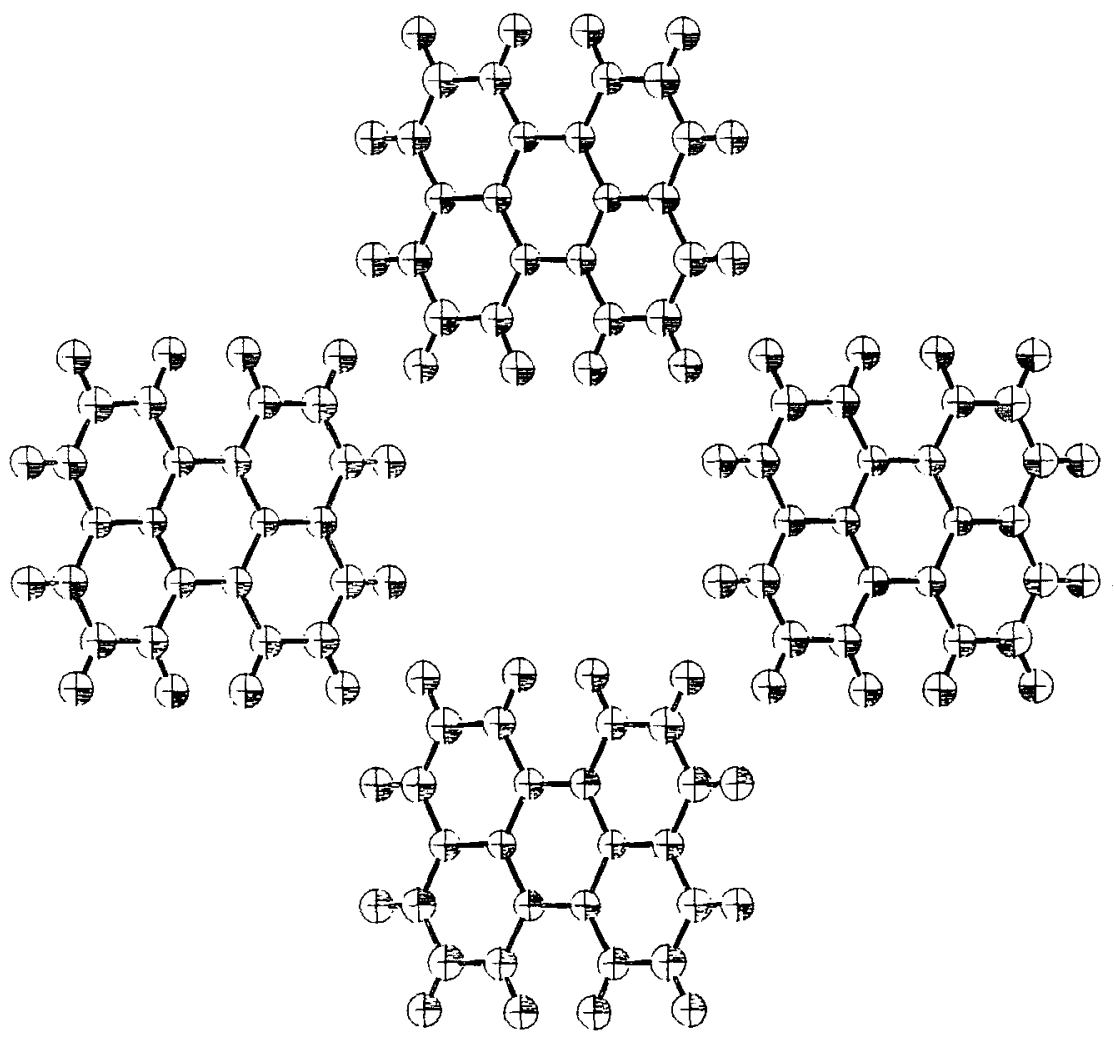

FIGURE 7 Projection of the unit cell on the be-plane (anions are omitted). 


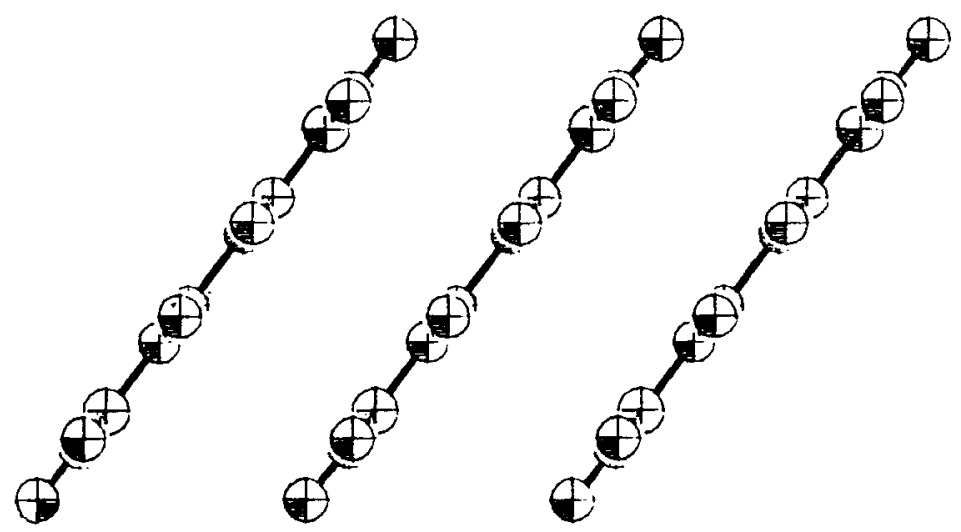

FIGURE 8 Projection of a cationic stack onto the ac plane.

filling of the space in the channels. As the anions are disordered, the found distances and angles (AsF: 1.63, 1.70, 1.81 and F-As-F: 92.3, 94.4, 93.9) are not very reliable.

\section{DISCUSSION}

It is well known that perylene can easily be oxidized by halogens-especially bromine $^{20-24}$ and iodine $e^{20,23,25-31}$ - by different metal salts ${ }^{27,32-34}$ like antimonyhexachloride, ${ }^{32-35}$ silverperchlorate ${ }^{34}$ and electrochemically. ${ }^{4,6}$ Though it has been pointed out very early that some of these oxidized solids are quite good electrical conductors (at least compared to other typical organic compounds, which are insulators), ${ }^{22}$ detailed physical and structural data on single crystals, so far have only been obtained for $(\mathrm{pe})_{2} \mathrm{Pt}(\mathrm{mnt})_{2}$ $\left(\mathrm{mnt}=\right.$ anion of dithiomaleodinitrile). ${ }^{19}$ The latter solid was obtained by oxidizing perylene with iodine in the presence of tetra- $n$-butylammonium$\mathrm{Pt}(\mathrm{mnt})_{2},{ }^{36}$ as well as electrochemically. ${ }^{6}$ The principle arrangement of peryleniumyl cations in the hexafluoroarsenate $(\mathrm{V})$ and hexafluorophosphate $(\mathrm{V})$ is very similar to the columns in $(\mathrm{pe})_{2}\left[\mathrm{Pt}(\mathrm{mnt})_{2}\right] .{ }^{19}$

The d.c.-conductivities parallel to the a-axes of all crystals of (1), (2), (3) and (4) in the temperature range between 300 and $190 \mathrm{~K}$ show a metalliclike behaviour. Below $190 \mathrm{~K}$ the conductivities of the crystals decrease with decreasing temperatures. In this semiconducting region the conductivity of the crystals of (1) and (2) depend on the "shape" of the crystals. In the case of the thicker crystals (type two) of (1) and (2) a sharp drop of the conductivity at a temperature of about $110-120 \mathrm{~K}$ is observed. The thinner crystals (type one) of (1), and (2) show a smooth decrease in the conductivity with decreasing temperature below $190 \mathrm{~K}$. The observed activation energies in the semiconducting region are smaller for (3) and (4) than for (1) and (2) (see Figure 2-4). Nevertheless, this activation energies are very similar to 
the one estimated from the ESR-measurements. Temperature cycling experiments between 300 and $50 \mathrm{~K}$ have shown a degradation of the room temperature conductivity which was particularly sensitive for those crystals of (1), (2), (3), and (4) which primarily showed the highest conductivities. Similar observations were made earlier for other one-dimensional organic metals. ${ }^{37}$

The relatively high conductivities of these compounds are possibly connected with the nonintegral formal oxidation numbers on the organic part of the structure. The "substitution" of some of the counter anions (like $\mathrm{PF}_{6}^{-}$or $\left.\mathrm{AsF}_{6}^{-}\right)$in the channels by neutral solvent molecules $\left(\mathrm{CH}_{2} \mathrm{Cl}_{2}\right.$ or THF) leads to a mixed valence state for the cationic stacks. This mixed valence state which is recognized as a prerequisite for high conductivities, ${ }^{9-11}$ is normally brought about by partial charge transfer but in the cases discussed here determined by stoichiometry. In this respect it is not surprising that crystals with different $\mathrm{CH}_{2} \mathrm{Cl}_{2} / \mathrm{PF}_{6}^{-}$or different $\mathrm{CH}_{2} \mathrm{Cl}_{2} / \mathrm{AsF}_{6}^{-}$ratios show different d.c. conductivity behaviour (type one and type two crystals of (1) and (2)), (see Sections 2.1.3.1; 2.1.4.1 and 2.3).

In by far the most highly conducting organic charge transfer complexes one observes very sharp epr lines, only very few exceptions are known. ${ }^{38,39}$ A linewidth of 0.6 Gauss as in our case thus clearly hints to a rather strong exchange interaction between neighbouring molecules. This interaction apparently leads to a metallic-like behaviour between $300 \mathrm{~K}$ and $190 \mathrm{~K}$ as can be seen from temperature independent paramagnetism and conductivity data. Such a temperature independent paramagnetism has been likewise observed in NMP-TCNQ, ${ }^{40}$ a well-known organic metal. The similarity of the magnetic properties of NMP-TCNQ and (1) is also apparent from the temperature dependence of the linewidth. We are thus quite sure that (1) can be considered as an organic metal at higher temperatures whereas it behaves as a paramagnetic semiconductor at temperatures below $190 \mathrm{~K}$.

The hexafluoroantimonate (V) salt (5) which differs in composition from (1)-(4) shows a d.c. conductivity which is about two orders of magnitude lower than those of (1)-(4). Consistent with this observation is the result of electrocrystallization experiments using $\mathrm{SbF}_{6}^{-}$as counterion: only small black prisms covering the electrode have been obtained (see Section 2.1.5).

\section{CONCLUSION}

Electrocrystallization is a valuable tool in the search for new highly conducting solids. This method selects crystals with the highest electrical conductivities and not those with the lowest free energies under the experimental conditions as found by using chemicals as oxidation agents. 


\section{Acknowledgements}

We would like to thank Deutsche Forschungsgemeinschaft, Bonn-Bad Godesberg, and Stiftung Volkswagenwerk for financial support. The help of P. Hagg and R. H. Harms in preparing Figure $\mathbf{I}$ is gratefully acknowledged.

\section{References}

1. F. Beck, Elektroorganische Chemie, Verlag Chemie, 1974.

2. Free Radicals, ed. J. K. Kochi, John Wiley, N.Y. 1973.

3. Methods in Free Radical Chemistry, Vol. 3, ed. E. S. Huyser, Marcel Dekker, N.Y. 1972.

4. T. C. Chiang, A. H. Reddoch, and D. F. Williams, J. Chem. Phys., 54, 2051 (1971).

5. C. V. Ristagno and H. J. Shine, J. Org. Chem., 36, 4050 (1971).

6. L. Alcacer and A. H. Maki, J. Phys. Chem., 78, 215 (1974).

7. H. P. Fritz, H. Gebauer, P. Friedrich, P. Ecker, R. Artes, and U. Schuibert, Z. Naturforsch., 33b, 498 (1978).

8. a) D. Jerome, A. Mazaud, M. Ribault, and K. Bechgaard, J. Physique Lettres, 41, L-95 (1980). b) K. Bechgaard, unpublished results.

9. Chemistry and Physics of One-dimensional Metals, ed. H. J. Keller, NATO-ASI Series, Vol. 25B, Plenum Press, N.Y. 1977.

10. Synthesis and Properties of Low-dimensional Materials, ed. J. S. Miller and A. J. Epstein, Ann. N.Y. Acad. Sci., 313 (1978).

11. Molecular Metals, ed. W. A. Hatfield, NATO-Conference Series VI: Materials Science, Vol. 1, Plenum Press, N.Y. 1979.

12. J. S. Miller, Science, 194, 189 (1976).

13. J. M. Williams, D. P. Gerrity, and A. J. Schultz, J. Am. Chem. Soc., 99, 1668 (1977).

14. J. E. Lind, jr., H. A. A. Abdel-Rehim, J. Phys. Chem., 70, 3610 (1966).

15. W. Lange and K. Askitopoulos, Z. Anorg. Allg. Chem., 223, 369 (1935).

16. L. B. Coleman, J. A. Cohen, A. F. Garito, and A. J. Heeger, Phys. Rev., B7, 2122 (1973).

17. L. B. Coleman, Rev. Sci. Jnstrument, 46, 1125 (1975).

18. A. Camermann and J. Trotter, Proc. Roy. Soc.; A279, 129 (1964).

19. L. Alcácer, D. Chasseau, and J. Gaultier, in preparation.

20. K. Brass and E. Clar, Ber., 65, 1660 (1932), Ber., 69, 1977 (1936).

21. A. Zinke and A. Pongratz, Ber., 69, 1591 (1936) and Ber., 70, 214 (1937).

22. H. Akamatu, H. Inokuchi, and Y. Matsunaga, Nature, 173, 168 (1954).

23. H. Akamatu, H. Inokuchi, and Y. Matsunaga, Bull. Chem. Soc. Japan, 29, 213 (1956).

24. T. N. Anderson, D. W. Wood, R. C. Livingston, and H. Eyring, J. Chem. Phys., 44, 1259 (1966).

25. T. Uchida and H. Akamatu, Bull. Chem. Soc. Japan, 34, 1015 (1961) and earlier references cited therein.

26. J. Kommandeur and F. R. Hall, Bull. Am. Phys. Soc., 4, 421 (1959) and J. Chem. Phys., 34, 129 (1961).

27. M. S. Frant and R. Eiss, J. Electrochm. Soc., 110, 769 (1963).

28. S. Aronson, J. S. Mittelman, and F. B. Bramwell, J. Inorg. Nucl. Chem., 39, 1095 (1977).

29. H.-C. I. Kao, M. Jones, and M. M. Labes, J.C.S. Chem. Comm., 1979, 329 (1979).

30. R. C. Teitelbaum, S. L. Ruby, and T. J. Marks, J. Amer. Chem. Soc., 101, 7568 (1979) and references cited therein.

31. P. Coppens in Extended Linear Chain Compounds, ed. J. S. Miller, Plenum Press, N.Y., in preparation.

32. K. Brass and E. Tengler, Chem. Ber., 64, 1650 (1931).

33. G. E. Blomgren and J. Kommandeur, J. Chem. Phys., 35, 1636 (1961).

34. Y. Sato, M. Kinoshita, M. Sano, and H. Akamatu, Bull. Chem. Soc. Japan, 42, 3051 (1969).

35. S. Hilpert and L. Wolf, Ber. deut. chem. Ges., 46, 2215 (1913).

36. L. Alcácer, H. Novais, and F. Pedroso, in Molecular Metals, ed. W. A. Hatfield, pp. 415. 
37. M. J. Cohen, L. B. Coleman, A. F. Gaxito, and A. J. Heeger, Phys. Rev., 10B, 1298 (1974).

38. Y. Tomkiewicz and E. Engler, Bull. Am. Phys. Soc., 20, 497 (1975).

39. R. B. Somoano, A. Gupta, and V. Hadek, J. Chem. Phys., 63, 4970 (1975).

40. A. J. Epstein, S. Etemad, A. F. Garito, and A. J. Heeger, Phys. Rev., B5, 952 (1972). 